\title{
A Transient Postmamillary Component of the Rat Fornix During Development: Implications for Interspecific Differences in Mature Axonal Projections
}

\author{
Brent B. Stanfield, Barry R. Nahin, ${ }^{\mathrm{a}}$ and Dennis D. M. O'Leary \\ The Salk Institute for Biological Studies, San Diego, California 92138
}

\begin{abstract}
We have used anterograde and retrograde tracing techniques to study the development of the postcommissural fornix in albino rats. The fornix reaches the caudal hypothalamus a day or two before birth. Before fornix axons can be seen entering the mamillary nuclei, a prominent contingent of the fornix can be followed beyond the mamillary bodies. This postmamillary component continues to grow into the midbrain and pontine tegmentum during the first postnatal week as the projection to the mamillary nuclei is being elaborated. During the second and third postnatal weeks, the postmamillary component of the fornix becomes progressively smaller until it is completely eliminated. The cells of origin of this transient postmamillary component of the fornix are found within the subicular complex of the hippocampal region. Most, if not all, of the cells of origin of the postmamillary component of the fornix survive the period during which this projection is eliminated.

Consistent with these observations is the interpretation that the axons of the fornix that eventually enter and arborize within the mamillary nuclei and are maintained in the adult, arise during development as interstitial collaterals from parent fibers, the distal portions of which are subsequently eliminated.

While not present in adult rats, a postmamillary component of the fornix has been described in other species, such as the cat (Nauta, 1958). It would seem, therefore, that in this case the interspecific variations in projection patterns result from the differential elaboration and elimination of an initially quite similar pattern of connections.
\end{abstract}

During the course of a recent study of the transient pyramidal tract projection which arises in the occipital cortex of young rats (Stanfield and O'Leary, 1985), we noticed that, in those few cases in which the injected anterograde tracer had spread through the white matter of the occipital cortex to involve the underlying

\footnotetext{
Received Dec. 29, 1986; revised Apr. 6, 1987; accepted Apr. 10, 1987.

We should like to thank W. M. Cowan and R. W. Guillery for their critical comments on an early version of the manuscript. We should also like to acknowledge Mary Ann Lawrence for technical assistance, Kris Turlock for photographic assistance, and Pat $\mathrm{I}$ homas and Nancy Goodknight for help with the manuscript. This work was supported by NIH Grants NS-18506 and EY-03653 and by Grant I-1035 from the March of Dimes.

Correspondence should be addressed to Dr. Brent B. Stanfield, NIH Animal Center, P.O. Box 289, Poolesville, MD 20837.

a Present address: The George Washington University School of Medicine and Health Sciences, Washington, D.C. 20037.

b Present address: The McDonnell Center for Studies of Higher Brain Function, Department of Neurosurgery, Washington University School of Medicine, 660 South Euclid Avenue, St. Louis, MO 63110.

Copyright (C) 1987 Society for Neuroscience $0270-6474 / 87 / 103350-12 \$ 02.00 / 0$
}

subicular complex, substantial amounts of transported label could be followed through the postcommissural fornix. This, in itself, was not surprising, since it has been known for more than 10 years that the postcommissural fornix ${ }^{1}$ arises in these retrohippocampal fields rather than in the hippocampus proper (Swanson and Cowan, 1975, 1977). However, what was totally unanticipated was the finding that whereas in adult animals the postcommissural fornix extends only as far as the mamillary bodies, in animals in which the tracer had been injected during the first postnatal week and the animals killed a few days after, a large contingent of labeled fibers could be followed through the postcommissural fornix to well past the level of the mamillary bodies, into the midbrain and pontine tegmentum.

Since this projection is maintained in some species (for example, see Nauta, 1958), the transient appearance of a postmamillary component of the fornix in young rats suggested to us an important general principle underlying the development of a major forebrain fiber system. Thus, we prepared a number of additional animals, utilizing anterograde tracing techniques, to determine the distribution of these transient fibers and the time course of their extension and subsequent disappearance, and retrograde tracing techniques, both in short-term survival experiments, to determine the cells that give rise to the postmamillary fibers and, in long-term survival experiments, to determine the fate of the relevant cells.

We have found that this postmamillary component of the fornix in rats is most prominent in the first postnatal week and that during the subsequent several days it progressively attenuates until it is no longer detectable during the third postnatal week. The cells of origin of these transient postmamillary fibers are found within the subicular complex; especially within the dorsal subiculum. Many, if not all, of these subicular cells survive well beyond the stage at which the postmamillary component of the fornix is eliminated. It would thus appear that cell death does not play a major role in the elimination of this transient projection and that its elimination principally involves the selective loss of axon collaterals.

\section{Materials and Methods}

Timed pregnant female albino rats of the Sprague-Dawley strain were obtained from Zivic Miller (Allison Park, PA). The day of insemination (E0) was used to determine fetal ages and the day of birth (P0) was used to determine postnatal ages. This study involves experiments utilizing anterograde axonal tracing methods as well as experiments in which the retrogradely transported tracer, Fast blue, was used.

\footnotetext{
"We use the term "fornix" in the narrow sense of those components of the postcommissural fornix that arise within the hippocampal region, thereby excluding axons that may join the fornix but arise elsewhere.
} 


\section{Anterograde tracing experiments}

Peroxidase method. Wheat germ agglutinin conjugated to horseradish peroxidase (WGA-HRP; from Triticum vulgaris, conjugated to peroxidase type VI, Sigma) was injected into the vicinity of the dorsal subiculum in 81 experiments. In most of these, $0.02-0.05 \mu \mathrm{l}$ of a $1-5 \%$ solution of the tracer was injected into the brain through a $I \mu$ l Hamilton syringe; however, in a few cases the WGA-HRP was dissolved as a $2 \%$ solution in PBS and iontophoresed $(5 \mu \mathrm{A}$ for $15 \mathrm{~min})$ through a glass micropipette with a tip diameter of $25 \mu \mathrm{m}$. The smallest injections were made into the youngest animals, and increasingly larger injections were made with increasing age to maintain, as much as possible, a similar effective injection size.

Eight animals were injected on E20. The pregnant female was anesthetized with chloral hydrate $(3.5 \mathrm{mg} / \mathrm{gm}$ body weight) and placed on a heating pad. The lower abdomen was shaved and cleaned with alcohol. The distal portion of one uterine horn containing the distal-most fetus was gently manipulated through a midline incision and placed on gauze moistened with warm saline. Care was taken at all times to keep the uterus moist with warm saline. A small (3-4 mm) incision was made in the uterus over the head of the fetus. The head of the fetus was pulled through the incision and hand held while a $1 \mu$ l Hamilton syringe needle was passed through the fetal membranes and the skull and the injection was made. The fetus was then gently returned to the uterus and the uterine incision sutured closed. The same procedure was then followed on the next fetus. Following the injections, the abdominal muscles of the mother werc sutured and the skin incision closed. Sixteen to $24 \mathrm{hr}$ later the mother was reanesthetized, the abdominal incision was reopened and the fetuses were removed one at a time for perfusion.

Seventy-three animals were injected at ages ranging from $\mathrm{P} 0$ to $\mathrm{P} 30$ Animals younger than P8 were anesthetized with open ether, while the older animals were anesthetized with choral hydrate. The younger animals were hand held and the older animals were stabilized in a stereotaxic device while a small incision was made in the scalp and a small hole was made in the skull overlying the dorsal subiculum. After the injection the animals were allowed to recover on a heating pad before being returned either to their mother or, in the case of weanlings and older animals, to their cages. Sixteen to $28 \mathrm{hr}$ later the animals were reanesthetized and perfused through the aorta first with $0.9 \%$ saline and then with $0.5 \%$ paraformaldehyde $/ 2 \%$ glutaraldehyde in $0.1 \mathrm{M}$ phosphate buffer $\left(\mathrm{pH} \mathrm{7.3)}\right.$. The brains were removed and stored at $4^{\circ} \mathrm{C}$ in $10 \%$ sucrose in $0.1 \mathrm{M}$ phosphate buffer. The brains were frozen-sectioned (usually sagittally, but in some cases, coronally) at $50 \mu \mathrm{m}$. For the young brains every section was taken, but for the older animals, a one-in-three or a one-in-five series of sections was mounted on gelatin-subbed slides and processed for TMB histochemistry (Mesulam, 1978). Before the final postreaction rinse, the sections were counterstained with a modified Richardson's stain (Richardson et al., 1960). After drying overnight, the sections were rapidly dehydrated in $100 \%$ ethanol, cleared in xylenes, and coverslipped with DPX. The slides were stored in the dark, at $4^{\circ} \mathrm{C}$. A few of these cases were taken from our previous study of the transient occipital corticospinal projection (Stanfield and O'Leary, 1985), but most were newly prepared.

Autoradiographic method. In 79 animals, ranging in age from $\mathrm{P0}$ to $\mathrm{P} 18,{ }^{3} \mathrm{H}$-proline was injected into the region of the dorsal subiculum. The animals were anesthetized and prepared for injection as above. In most cases, $5 \mu \mathrm{Ci}$ of ${ }^{3} \mathrm{H}$-proline (L- $\left[2,3-{ }^{3} \mathrm{H}\right](N)$ proline; specific activity, 30) $\mathrm{Ci} / \mathrm{mm}$; New England Nuclear) was injected in a volume of $0.05 \mu \mathrm{l}$, but in some of the P18 animals as much as $20 \mu \mathrm{Ci}$ in $0.2 \mu \mathrm{l}$ was injected. In all cases the isotope was dried by vacuum centrifugation, reconstituted with distilled water, and injected through a blunt-tipped $1 \mu \mathrm{l}$ Hamilton syringe. Between 12-24 hr later, the animals were reanesthetized; most were perfused through the aorta with $0.9 \%$ saline followed by $10 \%$ buffered neutral formalin, but a few of the younger animals were anesthetized and decapitated, and their brains fixed in Carnoy's. Most of the brains were processed for paraffin sectioning. Following dehydration, these brains were cleared in amyl acetate, embedded in paraffin, and sectioned sagitally at $15 \mu \mathrm{m}$. A one-in-five series of sections was mounted and deparaffinized. A few brains were frozen-sectioned these were sectioned sagittally at $40 \mu \mathrm{m}$, and a one-in-four series of sections was mounted and defatted.

The slides from all of the cases were coated with Kodak NTB-2 nuclear tract emulsion and stored at $4^{\circ} \mathrm{C}$ for 4 wecks. The slides were developed in Kodak D-19 at $16^{\circ} \mathrm{C}$ and fixed in Ektaflo, and the sections were stained through the emulsion with thionin before being dehydrated and coverslipped (Cowan et al., 1972). A number of these cases had been processed during a previous study (Stanfield and O'Leary, 1985), but the remainder were newly prepared.

\section{Retrograde tracing experiments}

We utilized the retrogradely transported fluorescent dye, Fast blue, as either an acute or a long-term marker in 38 experiments. In 33 of these cases the tracer was injected on P4. The rat pups were anesthetized with open ether, an incision was made in the scalp, a small hole was made in the skull, and the needle of a $1 \mu \mathrm{l}$ Hamilton syringe was lowered into the region of the midbrain and pontine tegmentum. Between 0.1 and $0.3 \mu \mathrm{l}$ of a $2 \%$ suspension of Fast blue was injected, the Hamilton syringe withdrawn, and the wound sutured closed. The pups were kept warm on a heating pad until they recovered from the anesthesia and could be returned to their mother. In 15 of these cases the pups were reanesthetized after a $3 \mathrm{~d}$ survival period and perfused through the aorta with $0.9 \%$ saline followed by $10 \%$ neutral buffered formalin. The remaining 18 animals were perfused on P22. The brains were removed and stored in $15 \%$ sucrose in $10 \%$ neutral buffered formalin at $4^{\circ} \mathrm{C}$.

An additional $S$ animals were injected on P18. These animals were anesthetized with $3.5 \%$ chloral hydrate and placed in a stereotaxic device. The scalp was shaved and incised, and a burr hole was made in the skull with a Dremel drill. The needle of a Hamilton syringe was lowered in the region of the midbrain and pontine tegmentum, and 0.3 $\mu 1$ of a $2 \%$ suspension of Fast blue was slowly injected. After the injection the scalp was sutured closed and the animals were returned to their cages. On P22 these animals were reanesthetized and perfused as above.

The brains from all of these experiments were frozen-sectioned sagittally at $30 \mu \mathrm{m}$. Two one-in-five series were mounted, and the sections were examined and photographed under UV epi-illumination on a Nikon Optiphot microscope equipped with fluorescence illumination and a $100 \mathrm{~W}$ mercury bulb.

\section{Results}

Anterograde tracing experiments

Since the observations made in the experiments involving ${ }^{3} \mathrm{H}$ proline are consistent with those obtained with WGA-HRP, we shall avoid repetition by presenting the results of these parallel series of experiments together rather than separately.

In the animals in which the subicular complex was injected with an anterograde tracer on E20, there is a substantial amount of transported marker within the postcommissural fornix. The caudal extent of the labeled fibers within the diencephalon varies somewhat among the 8 fetal brains. In some cases, labeled fibers can be followed only to about midway between the anterior commissure and the mamillary bodies, while in other fetuses from the same litter, heavy labeling continues through the hypothalamus and only begins to attenuate near the level of the mamillary complex (Fig. 1). This intercase variability may result from real differences among animals in the progress of the development of the brain, but we cannot eliminate the possibility that it is due to differences in the completeness of filling of the labeled developing axons.

In none of the cases in which the labeling extends as far as the caudal hypothalamus is there any evidence of label within the mamillary nuclei themselves (Fig. 1). Rather, the labeled axons remain confined to a fairly sharply defined fiber bundle at the dorsolateral aspect of the mamillary nuclei. As they pass toward the caudal aspect of the mamillary complex, they turn medially and actually extend slightly beyond the mamillary nuclei, alongside the interpeduncular fossa (Fig. 1C). Here the number of labeled fibers diminishes rapidly, and in no case is label seen caudal to the interpeduncular fossa.

The apparent number and extent of labeled fibers that continue past the mamillary bodies are much greater in animals injected on the day of birth (Figs. 2-4). As in the fetal animals, the labeled fibers turn medially, fairly abruptly, near the caudal end of the mamillary complex (Fig. 2), and approach the midline 

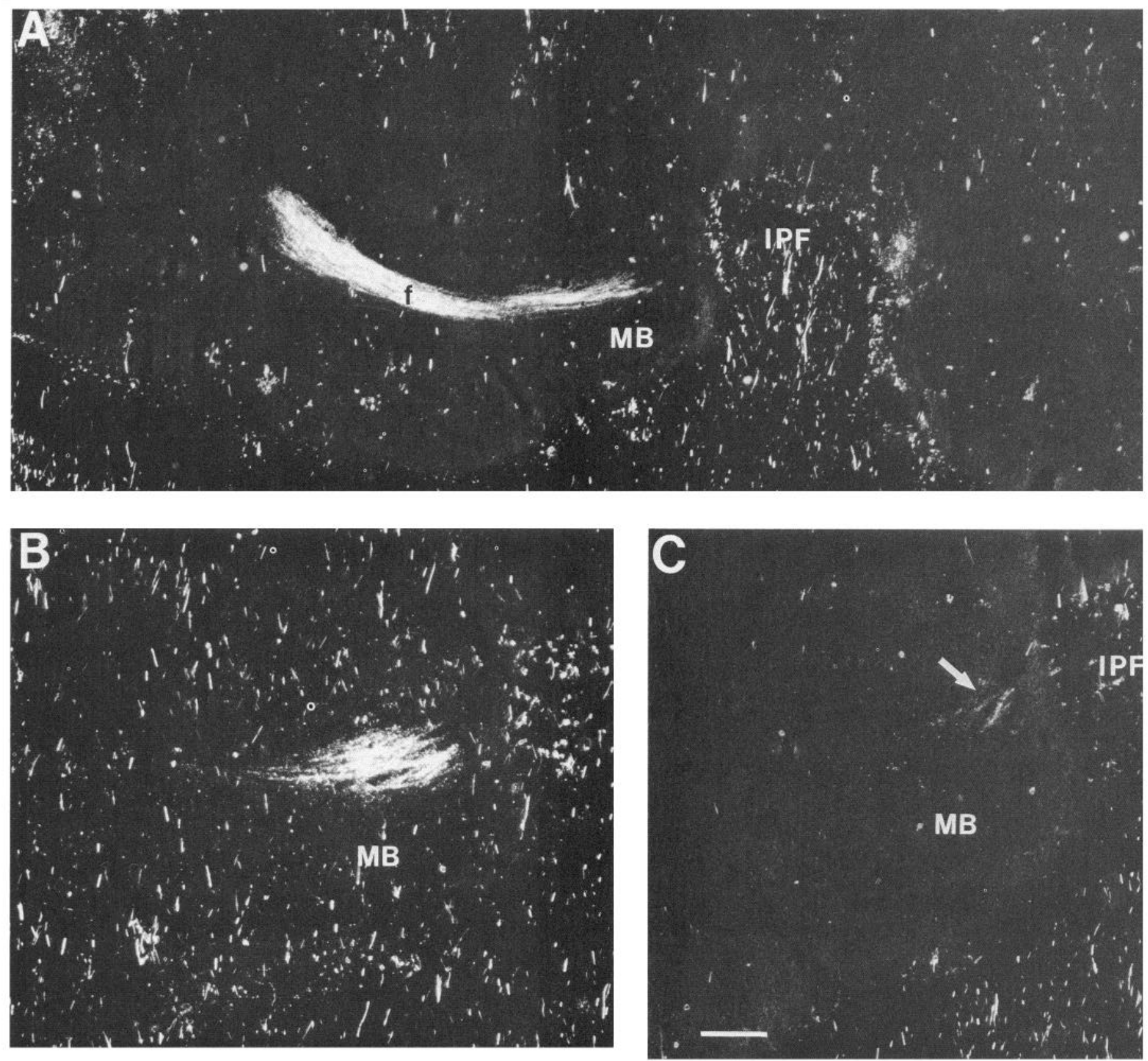

Figure 1. Dark-field photomicrographs of sagittal sections through the brain of a fetal rat injected with WGA-HRP into the dorsal subiculum on E20 and killed on E21. In this and subsequent figures, sagittal sections are shown with rostral to the left. In this case, labeled fibers can be followed to the caudal hypothalamus $(A)$, where they pass above the mamillary bodies at their lateral margin $(B)$. Note the absence of label within the mamillary bodies. Some labeled fibers continue caudal to the mamillary bodies (C). Scale bar in $C=250 \mu \mathrm{m}$ in $A ; 150 \mu \mathrm{m}$ in $B$ and $C$. See Appendix for abbreviations used here and in the other figures.

in the region of the supramamillary decussation (the posterior hypothalamic decussation of Ganser, 1882). Here most turn sharply dorsally and some cross the midline. Beyond the supramamillary decussation, the bundle of labeled axons divides into several fascicles, all of which continue caudally medial to the fasciculus retroflexus (Figs. 3, 4). Just above the interpeduncular nucleus these fascicles of labeled axons fan out in the midbrain tegmentum and, in most cases, can be followed no further. However, in some animals at this age, labeled fascicles continue caudally into the pons, near the region of the medial raphe nucleus. In a few cases, some labeled axons can be fol- lowed from the region of the supramamillary decussation directly dorsally, near the midline, at the level of the nucleus of Darkschewitsch. As far as we can determine, these variations in the distribution and extent of the postmamillary component of the fornix bear no simple relationship to the location or size of the injection site within the subicular complex.

In the animals injected on the day of birth, there is, for the first time, some light labeling within the mamillary nuclei. At this age the amount of this labeling is quite small, and, in addition, it is only present close to the labeled fiber bundle (Figs. $3 B, 4 B$ ); most of the mamillary gray itself is unlabeled. Neither 


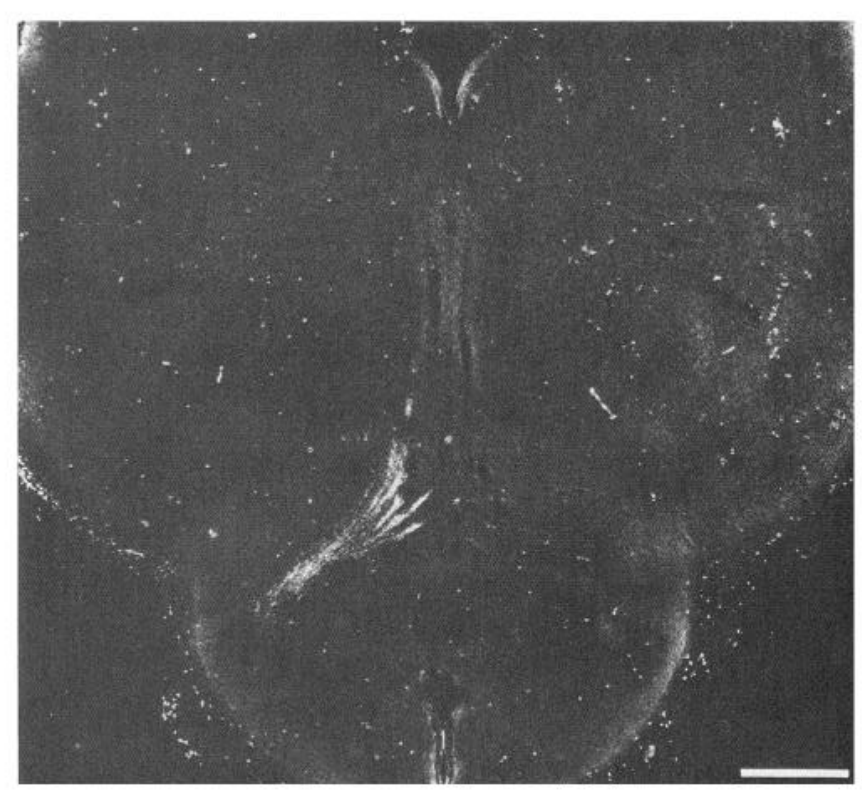

Figure 2. Dark-field photomicrograph of a coronal section through the caudal end of the mamillary bodies from the brain of a rat injected with WGA-HRP into the subiculum on P0. The labeled fibers in the fornix turn abruptly toward the midline at this level. Scale bar, $0.5 \mathrm{~mm}$.

at this, nor at subsequent ages, are labeled fibers seen in either the principal mamillary tract (Fig. $3 C$ ) or the mamillary peduncle, in which the efferent projections of the mamillary nuclei are found.

The distribution of the postmamillary fornix continues to expand during the first few postnatal days. In animals injected on P3, one finds the same 2 contingents of fibers of the postmamillary fornix that were present in those $\mathrm{P} 0$ injected animals, which displayed the widest distribution (Figs. 5, 6). The largest contingent of labeled fibers curves caudally from the region of the supramamillary decussation medial to the fasciculus retroflexus, where, as a number of separate fascicles, the labeled fibers continue above the interpeduncular nucleus and pass into the pons near the dorsal portion of the medial raphe nucleus (Fig. 6). Several fascicles of labeled fibers peel off dorsally from these bundles and pass to the rostral part of the mesencephalic central gray and to the dorsal part of the pontine tegmentum, in the region of the third nerve nucleus and the dorsal raphe nuclei (Fig. 6). A second, smaller, contingent of fibers leaves the region of the supramamillary decussation and arches dorsally to distribute fibers bilaterally through the region of the dorsal longitudinal fasciculus of Schütz to the rostral portion of the central gray (Fig. 6).

It should be emphasized that we do not know if any of the labeled fibers of the postmamillary component of the fornix form synapses anywhere along their distribution. It is worth noting, however, that there is no evidence in our WGA-HRP material of the fine dustlike reaction product that is commonly found within terminal fields in any of the regions within the

Figure 3. Dark-field photomicrographs of sagittal sections through the brain of a rat injected with WGA-HRP into the caudal cortex including the dorsal subiculum on P0. $A$, Center of the injection site. $B$, Labeled fibers within the fornix pass above the mamillary bodies, with only a
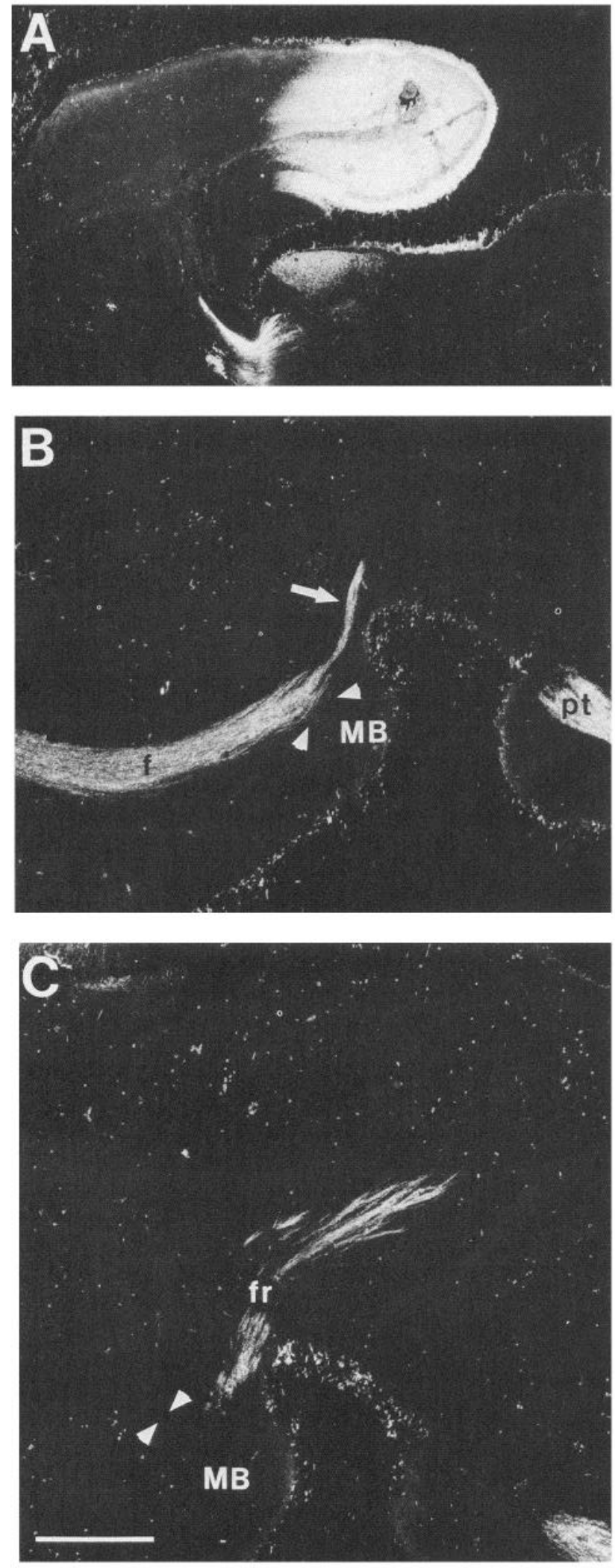

small amount of label present within the mamillary nuclei (between arrowheads), while a large contingent of labeled fibers extends caudal to the mamillary complex (arrow). $C$, Postmamillary fibers of the fornix fan out into the midbrain, passing just medial to the fasciculus retroflexus. Note the absence of label within the principal mamillary tract (between the arrowheads). Scale bar in $C=1.0 \mathrm{~mm}$ in $A ; 0.5 \mathrm{~mm}$ in $B$ and $C$. 

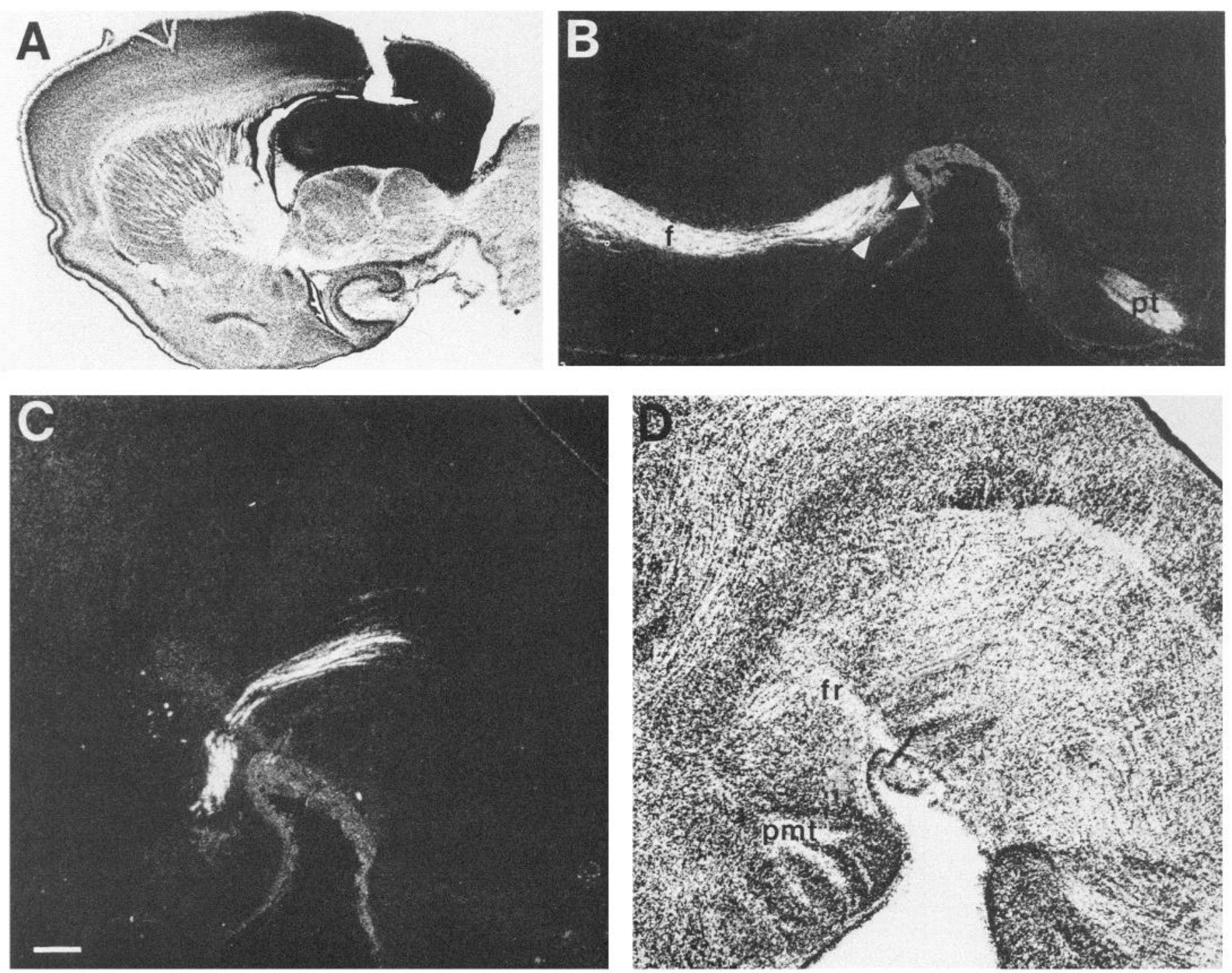

Figure 4. Photomicrographs of autoradiographs of sagittal sections through the brain of a rat injected with ${ }^{3} \mathrm{H}$-proline centered in the subiculum on P0. A, Center of the injection site. $B$, In this dark-field photomicrograph, the labeled fibers are shown passing dorsal to the mamillary bodies. Some label is seen with the mamillary nuclei (between arrowheads). Note that since the injection involved the occipital cortex, there is label present in the pyramidal tract due to the transient occipital corticospinal projection present at this stage (Stanfield and O'Leary, 1985). $C$ and $D$, Dark$(C)$ and bright-field $(D)$ photomicrographs of a section in which the labeled fibers of the postmamillary fornix fan out into the midbrain. Scale bar in $C=1.0 \mathrm{~mm}$ in $A ; 250 \mu \mathrm{m}$ in $B ; 200 \mu \mathrm{m}$ in $C$ and $D$.

distribution of the postmamillary fibers. After P1, however, such fine terminal labeling is present within the mamillary nuclei in all of the relevant brains (Figs. 5, 6). Nonetheless, we cannot rule out the possibility that some synapses are formed by these transient axons.

Over the next several days the number and the distribution of the fibers in the postmamillary fornix become progressively smaller. In animals injected on P9 the contingent of fibers that pass medial to the fasciculus retroflexus is still evident (Fig. 7), but it contains fewer labeled fibers than in the younger animals and the labeled axons cannot be followed as far caudally. This trend continues through the second and third postnatal week until the postmamillary component of the fornix is completely eliminated and the fornix system as a whole attains its adult configuration (Fig. 8).

\section{Retrograde tracing experiments}

To determine the cells of origin of the postmamillary component of the fornix, we injected the retrogradely transported fluorescent dye, Fast blue, into the midbrain and pontine tegmentum in a series of rat pups on P4 since the postmamillary fornix reaches its greatest extent at about this stage. The animals were killed after a $3 \mathrm{~d}$ survival period. The dye injections were aimed at the midline, and we were careful to ensure that the injections did not encroach upon the mamillary complex. In every brain large numbers of retrogradely labeled neurons can be seen in the subicular complex (Fig. 9A). The vast majority of labeled neurons is confined to the subiculum itself, but some labeled cells are seen in the other retrohippocampal fields. Interestingly, in most cases a few labeled neurons are also present in the deep 
part of the pyramidal cell layer of the regio superior of the dorsal hippocampus itself, but only near the subicular border of this field. Within the subiculum itself the labeled cells are concentrated dorsally, but many cells are seen at more ventral levels as well. When the dendrites of the cells are labeled, it is clear that the neurons are pyramidal in form (inset in Fig. 9A).

In a second group of rats, Fast blue was injected into the midbrain and pontine tegmentum at P18. When these animals were killed $4 \mathrm{~d}$ later, there was no evidence of retrograde labeling in the subiculum, or for that matter in any of the cortical regions included within the injection sites in our anterograde tracer experiments. There are, of course, many cells labeled in the cortical (Irle et al., 1984; Wyss and Sripanidkulchai, 1984; Torigoe et al., 1986a) and subcortical regions known to project to or through the midbrain and pontine tegmentum, including the mamillary complex itself (due to the involvement of the mamillotegmental tract: van der Kooy et al., 1978; Irle et al., 1984; Torigoe et al., 1986b).

Finally, to establish the fate of the cells that give rise to the early postmamillary fornix, we injected Fast blue into the midbrain and pontine tegmentum as before in a group of P4 rat pups but allowed these animals to survive until P22. In these brains there are large numbers of labeled neurons in the retrohippocampal fields with a distribution essentially indistinguishable from that seen in the similarly injected young animals with acute survival periods (Fig. 9B).

It is clear from this that most, if not all, of the cells giving rise to the postmamillary fornix survive for the first 3 weeks of postnatal life, and we therefore conclude that the elimination of the postmamillary fornix involves the selective elimination of axon collaterals that bypass the mamillary nuclei.

\section{Discussion}

The principal finding of this study is that in developing rats many of the axons in the postcommissural fornix initially overshoot the mamillary nuclei and during the first week of postnatal life fan out and extend into the midbrain and pontine tegmentum. Subsequently, this postmamillary component of the fornix is completely eliminated, and the adult distribution of the fornix is attained. Since the cells within the subicular complex that give rise to this transient projection survive beyond the third postnatal week, we conclude that the postmamillary fibers are axon collaterals and that they are selectively eliminated without the death of the parent neurons.

Before discussing the implications of these findings, some comments are needed about the techniques we have used to identify the postmamillary fibers and the cells that give rise to these, since the experiments, by necessity, involve using animals of different ages. For example, it might be argued that a postmamillary component of the fornix is actually present in adult rats, but for some technical reason, it can only be detected in young animals. This possibility is suggested by previous reports (based on axonal degeneration methods) of a postmamillary component to the fornix in rats (Nauta, 1956; Valenstein and Nauta, 1959). At least in some instances, these reports were undoubtedly complicated by the involvement in the experimental lesions of fibers that arose from structures other than the subicular complex. Most recent studies with axonal transport methods have provided no evidence for a postmamillary component to the fornix in adult rats (Swanson and Cowan, 1977; Torigoe et al., 1986a). Further, even in those degeneration stud-
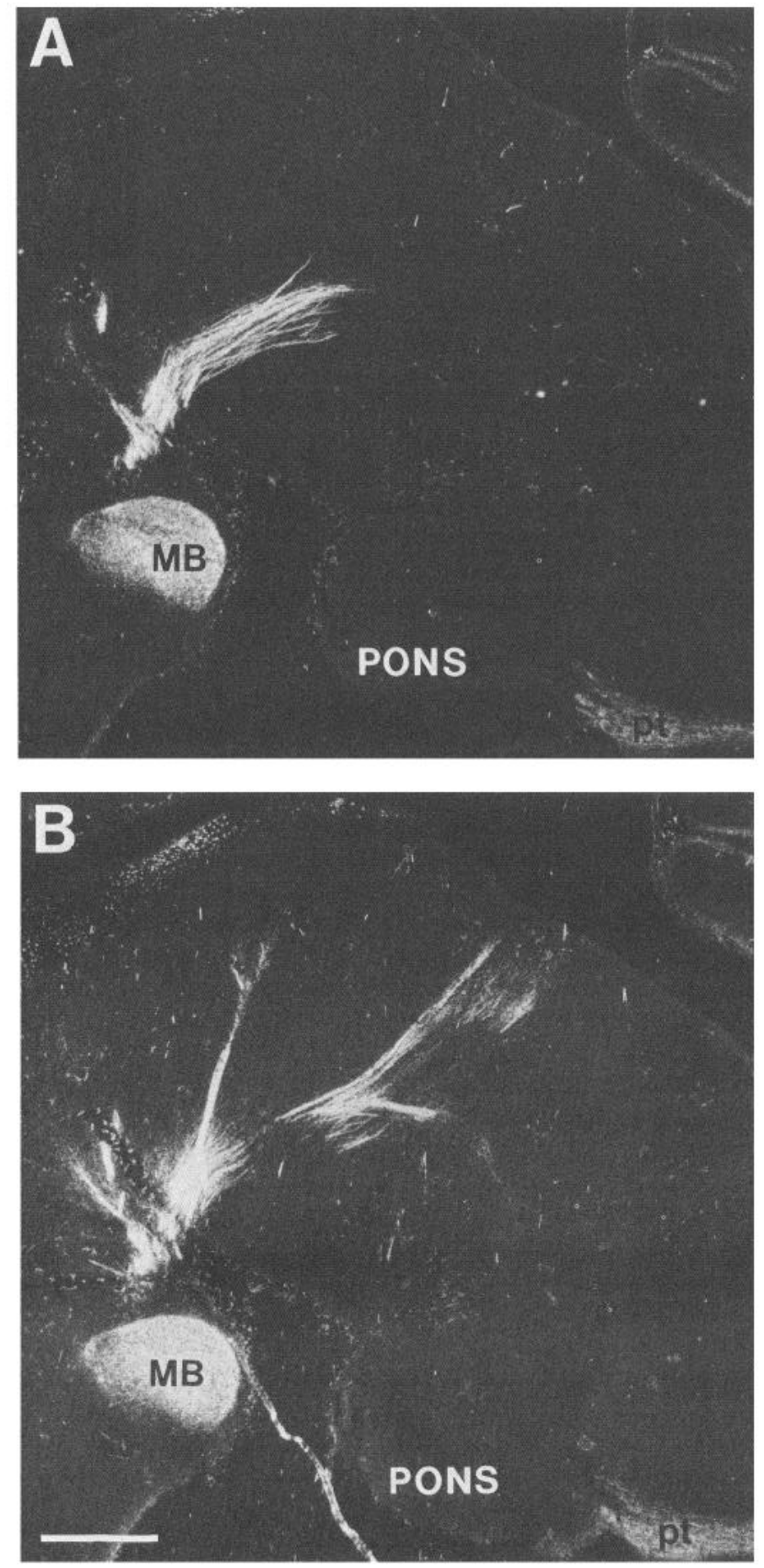

Figure 5. Dark-field photomicrographs of sagittal sections through the brain of a rat in which the WGA-HRP injection into the subicular complex was made on $\mathrm{P} 3$ and the animal killed on $\mathrm{P} 4$. A, Two fascicles of the postmamillary component of the fornix can be seen at this level. The larger bundle sweeps caudal into the midbrain, while the smaller contingent of fibers ascends fairly directly dorsal. $B$, In this more medial section the postmamillary component of the fornix is seen breaking into several smaller fascicles that extend further into the midbrain and pontine tegmentum. Note the marked increased labeling within the mamillary nuclei at this age. Scale bar, $0.5 \mathrm{~mm}$. 


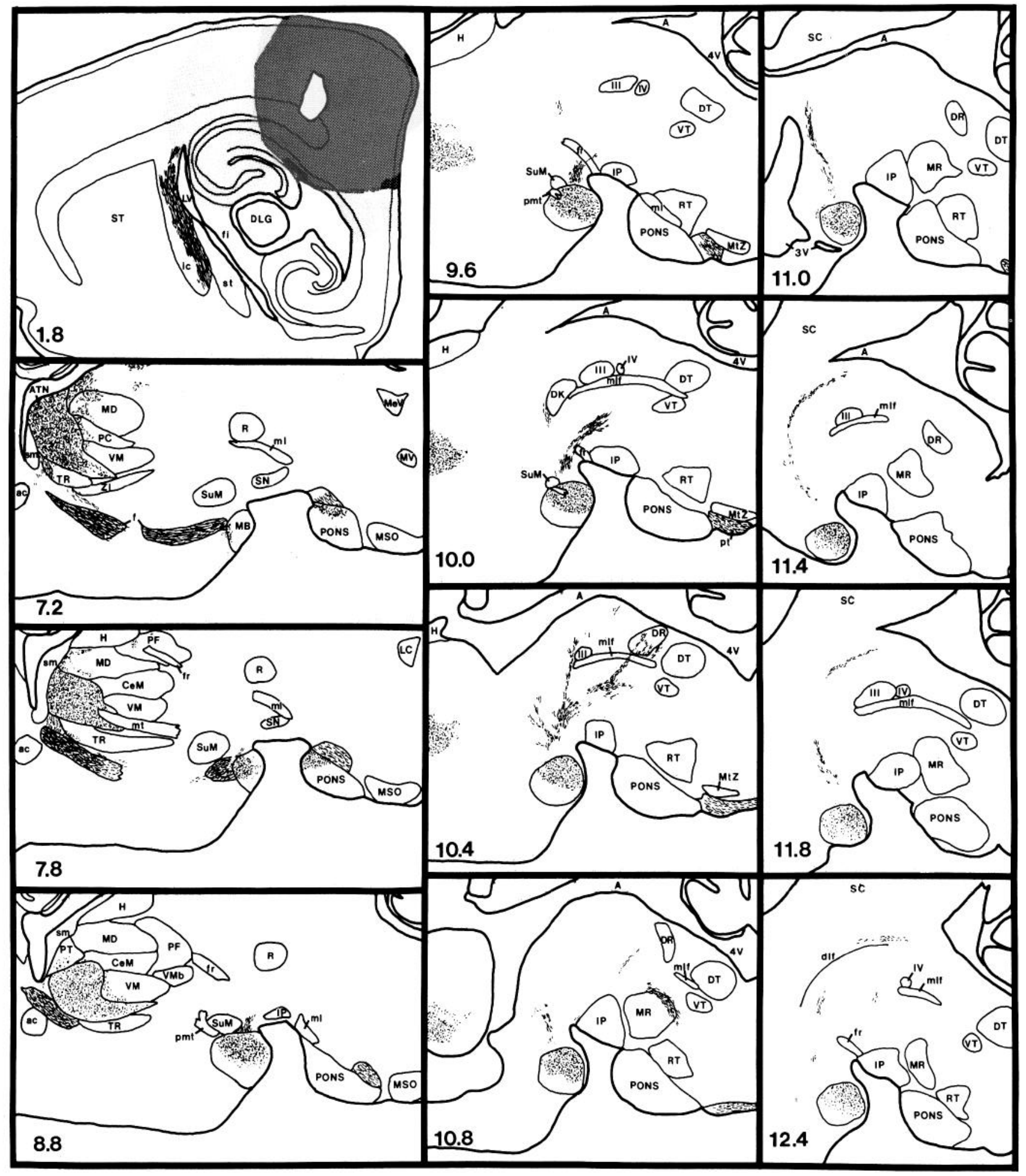

Figure 6. Camera lucida drawings of sagittal sections from the same case illustrated in Figure 5. The number in the lower left of each panel indicates the distance in millimeters from the first section collected.

ies identifying such a pathway in the rat, it is described as comprising substantially fewer fibers than found in the premamillary fornix (Nauta, 1956), while in our early postnatal material, the postmamillary component is quite prominent.

A second possibility that must be considered is that the post- mamillary labeling seen in our young animals may be the result of transneuronal spread of the label through some fiber system other than the fornix, such as through the septum or through the cells of the mamillary nuclei themselves; in fact, the distribution of the postmamillary labeling that we see does resemble 


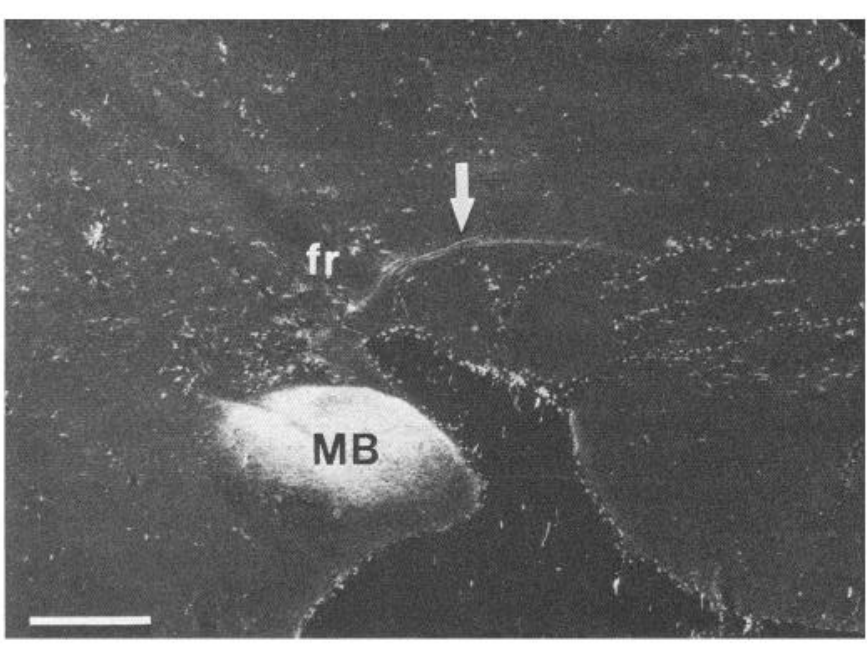

Figure 7. Dark-field photomicrograph of a sagittal section from the brain of a rat injected with WGA-HRP into the subicular complex on P9. Although heavy labeling is present in the mamillary bodies at this age, the postmamillary component of the fornix (arrow) is much reduced. Scale bar, $0.5 \mathrm{~mm}$.

the distribution of the mamillotegmental bundle (Cruce, 1977; Shen, 1983). There are several reasons for thinking that this is not the case. First, we can follow the labeled fibers within the fornix beyond the mamillary bodies in animals in which there is little labeling of the mamillary nuclei (Figs. 3, 4). Moreover, in these cases there is no sign of labeling within either the principal mamillary tract or the mamillary peduncle (Fig. $3 C$ ), in which the mamillary efferent axons pass. Last, the postmamillary component is intensely labeled even in cases with modest postinjection survival times that are likely to be too short to allow for any significant transneuronal spread of the label.

A third possibility is that the labeling seen in the WGA-HRP experiments is retrograde rather than anterograde since it is known that some of the regions to which the labeled fibers in the postmamillary fornix could be traced project to the forebrain (e.g., the raphe nuclei and the locus coeruleus). In fact, many retrogradely labeled neurons are seen in these regions in our material. Perhaps the strongest argument against this is the finding that the postmamillary fibers can be labeled by the injection of ${ }^{3} \mathrm{H}$-labeled amino acids into the subicular complex. Since this cannot lead to the retrograde labeling of axons, ${ }^{2}$ it seems fairly clear that we are dealing with an anterogradely labeled fiber system. Moreover, the labeled postmamillary fibers in our experiments follow a greatly different course from the trajectories of the efferents from the locus coeruleus and the raphe nuclei. For the most part, the latter travel outside the fornix (Azmitia and Segal, 1978). Perhaps most critical, however, is the finding that large numbers of retrogradely labeled neurons can be seen within the subicular complex only in those cases in which the tegmental injections of Fast blue were made at an age when label is detectable in the postmamillary component of the fornix.

Thus, we feel that our observations allow us to draw the following conclusions: (1) During the perinatal development of the rat, large numbers of subicular neurons extend axons through the fornix that initially grow beyond the level of the mamillary bodies and into the midbrain and pontine tegmentum; (2) the number and extent of these axons decrease during the second postnatal week, and this postmamillary component of the fornix is completely eliminated during the third postnatal week; and (3) many of the cells of origin of this pathway persist within the subiculum long after the postmamillary portion of their axons has been completely eliminated.

Although it seems likely, it remains to be demonstrated ex${ }^{2}$ Even in those instances in which ${ }^{3} \mathrm{H}$-proline is known to be transported ret-
rogradely, the axons themselves are not labeled at comparable survival times
(Künzle, 1977; LeVay and Sherk, 1983).
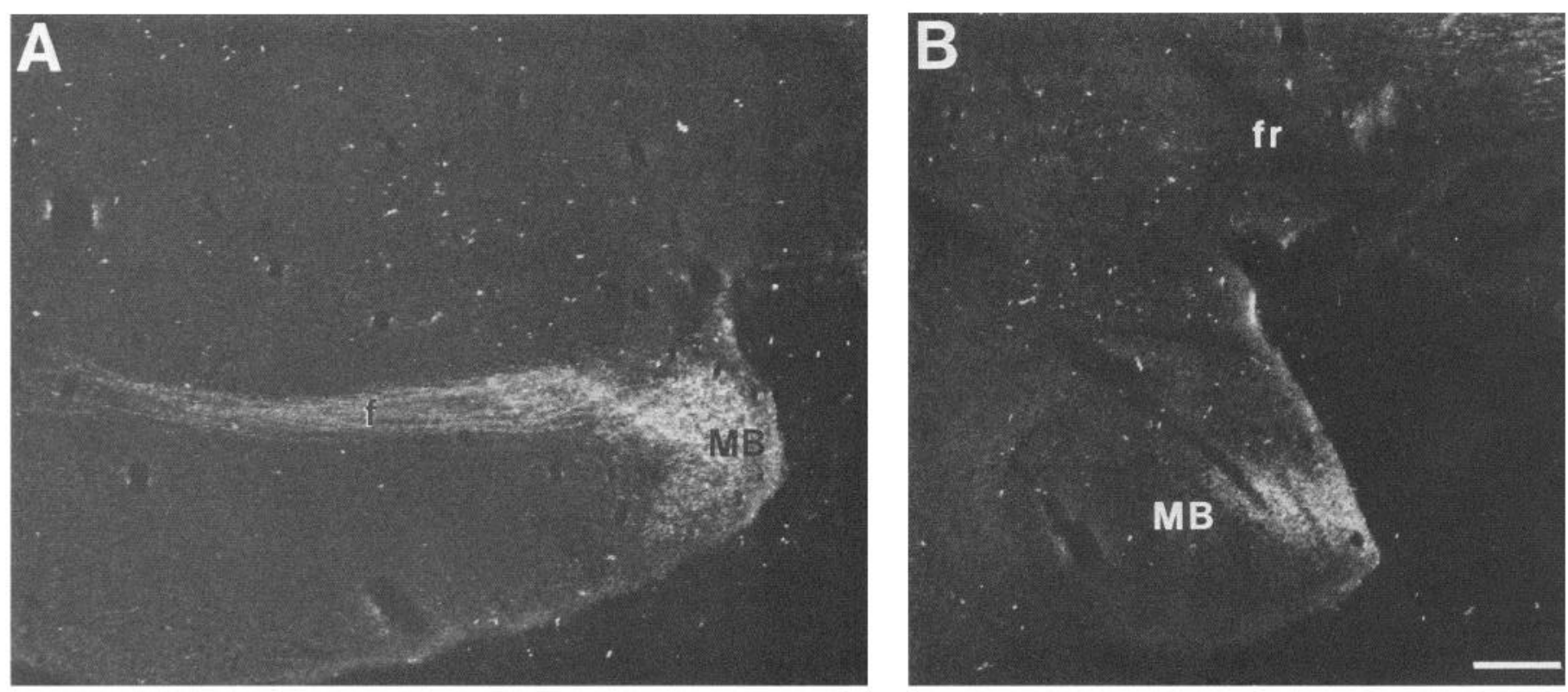

Figure 8. Dark-field photomicrograph of sagittal sections from the brain of a rat in which the subicular WGA-HRP injection was made on P17. Although label is found in the fornix $(A)$ and in the mamillary bodies $(A$ and $B$ ), there is no evidence for the presence of a postmamillary component to the hippocampal fornix at this age. Compare the absence of label around the fasciculus retroflexus ( $f r$ ) with what is seen during the early postnatal period (see Fig. 6). Scale bar, $250 \mu \mathrm{m}$. 

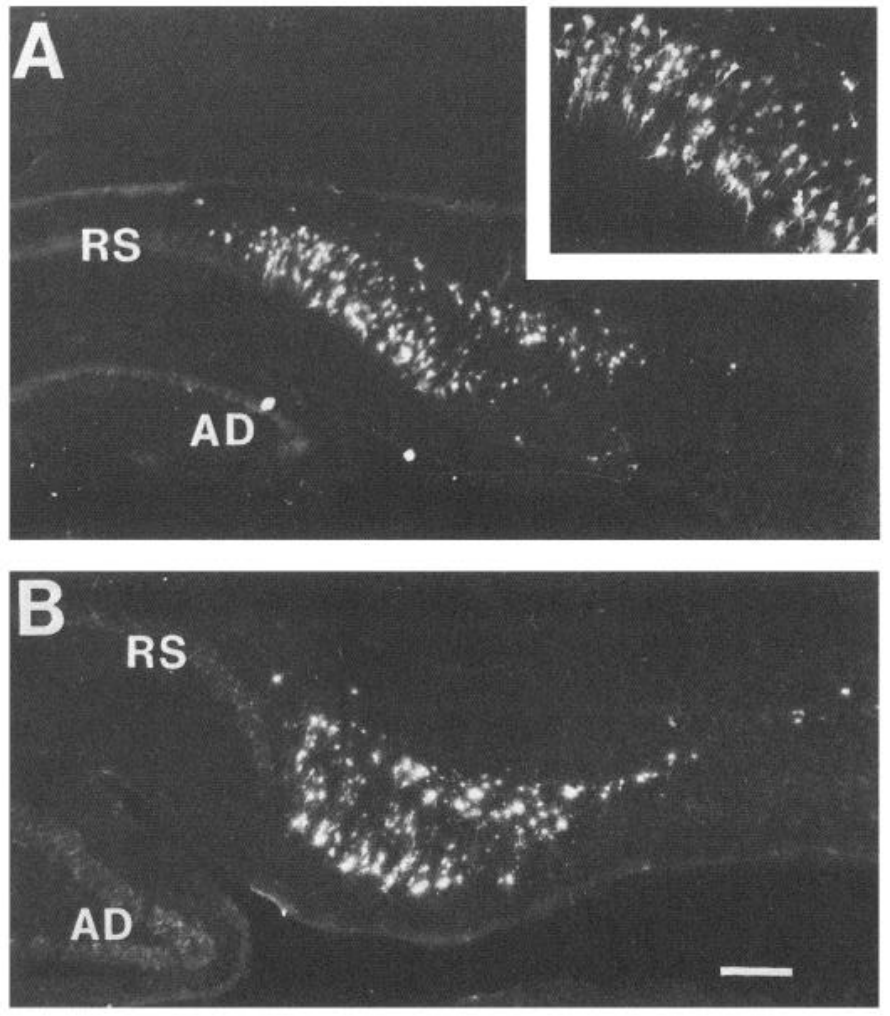

Figure 9. Fluorescence photomicrographs of sagittal sections through the subicular region of the brains of rats in which an injection of Fast blue was placed into the midbrain and pontine tegmentum on P4. A, This animal was killed on P7. Note the large number of retrogradely labeled neurons in the subiculum. Inset, at higher magnification, shows the evident pyramidal form of many of the labeled cells. $B$, This rat was allowed to survive until P22. Many of the labeled neurons are still present within the subiculum. Scale bar in $B=225 \mu \mathrm{m}$ in $A$ and $B ; 125$ $\mu \mathrm{m}$ for inset.

perimentally that the neurons within the subiculum that transiently extend axons through the fornix and into the midbrain and pontine tegmentum are the same cells which, in the adult, maintain a projection to the mamillary bodies. Certainly the locale of these neurons within the subicular complex (Meibach and Siegel, 1975; Swanson and Cowan, 1975, 1977; Donovan and Wyss, 1983), the fact that they extend axons during development that attain the level of the mamillary bodies, and the finding that they do not die, all argue toward this view, as does the observation that when the postmamillary component of the fornix is at its peak, and there is substantial labeling within the mamillary nuclei themselves, the labeling within the fornix does not attenuate as one follows the labeled fibers beyond the level of the mamillary bodies (Figs. 5,6). Therefore, it seems probable that the subicular neurons that transiently extend axons beyond the mamillary bodies do come to participate in the maintained projection to the mamillary bodies; however, confirmation of this must await experiments employing a delayed double-label paradigm such as has been used to approach similar questions in other systems (Ivy and Killackey, 1982; O'Leary and Stanfield, 1985; Stanfield and O'Leary, 1985).

If the axons of the postmamillary component of the fornix are indeed collaterals of the subicular axons that innervate the mamillary bodies, then one interesting aspect of our observations deals with the timing of the growth of these 2 collaterals. In the most advanced of our fetal cases, the labeled fibers have
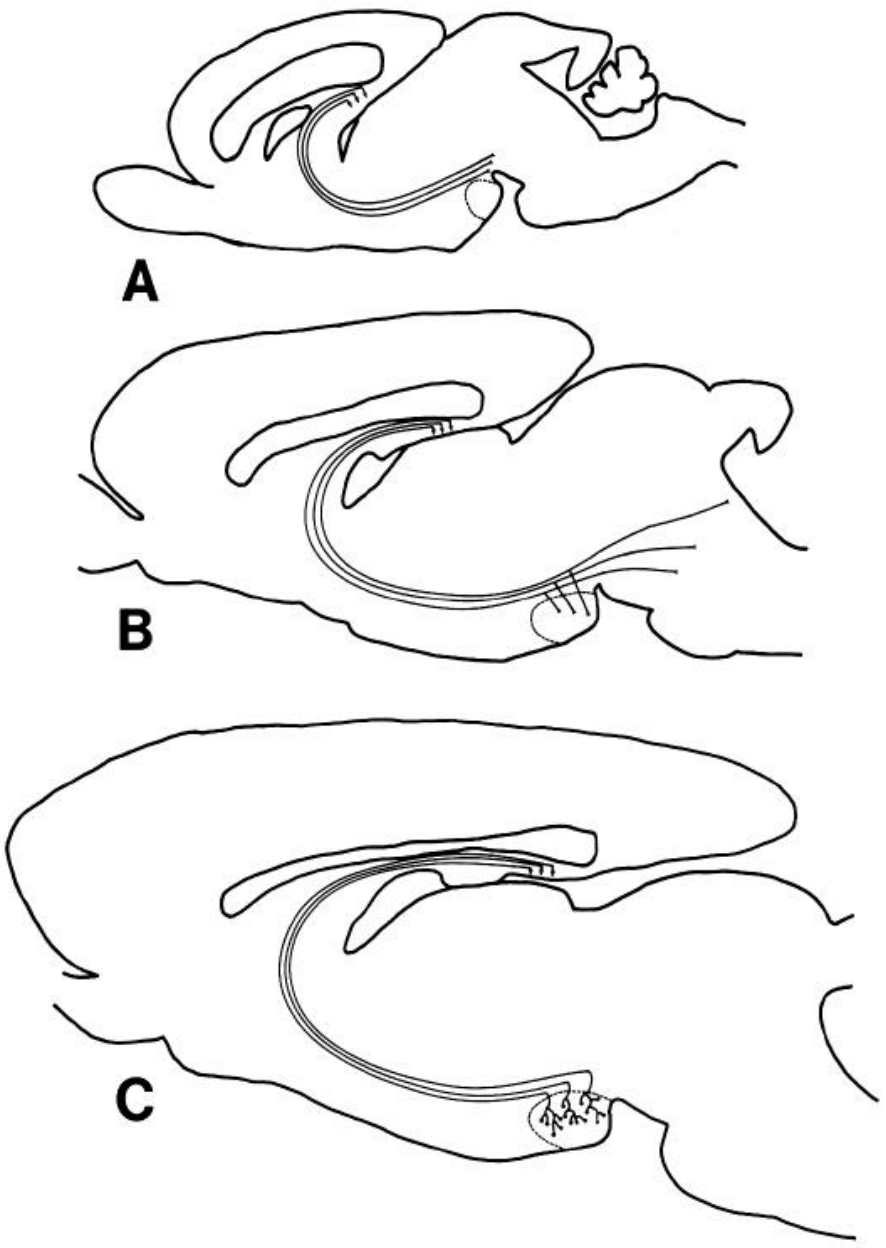

Figure 10. These schematic drawings illustrate some of our findings. $A$, When the developing fibers of the fornix first reach the level of the mamillary bodies, they extend past without entering into the mamillary nuclei. $B$, Over the next several days, the fibers of the fornix enter into the mamillary nuclei as well as continue their caudal postmamillary extension. $C$, Subsequently, the postmamillary component of the fornix is eliminated, while the definitive projection to the mamillary nuclei remains and is elaborated.

already passed the mamillary bodies (Fig. 1C), yet there is no hint of any label within the mamillary nuclei themselves. And in our newborn cases the postmamillary component of the fornix is well advanced, while there is minimal label present in the mamillary nuclei (Figs. 3, 4). Thus, one interpretation would be that the mamillary collateral that is elaborated and maintained actually originates as an interstitial sprout from the trunk axon which grows past the level of the mamillary bodies, the distal segment of which eventually being eliminated (Fig. 10).

It may seem somewhat counterintuitive that what will become the definitive collateral should arise as a secondary, interstitial sprout from a developing fiber. However, it is almost certainly true that axons utilize a cascade of cues in order to find their way to their target site, and it may be that a certain amount of time is needed before the cues that "attract" the axons to grow into their terminal zone can take over from the cues that had brought them so far along their course. Such a "waiting period" within the white matter before entry into the gray has repeatedly been seen during the development of cortical afferents, before those axons enter the developing cortex (Lund and Mustari, 
1977; Rakic, 1977; Wise et al., 1977; Wise and Jones, 1978; Killackey and Belford, 1979; Shatz and Luskin, 1986). Similarly, corticospinal axons are seen within the dorsal funiculus at a certain level of the spinal cord well before their entry within the spinal gray at that level (Reh and Kalil, 1981; Schreyer and Jones, 1982).

A situation even more comparable to the present case is revealed in observations we recently made on the development of the transient occipital corticospinal projection in rats and hamsters (Stanfield and O'Leary, 1985; O'Leary and Stanfield, 1986). Occipital cortical pyramidal tract axons extend well past the pons before any evidence of collateral entry into the pontine gray is seen. Only well after the corticopontine collaterals emerge, enter, and arborize within the basilar pontine nuclei, are the distal portions, i.e., the pyramidal tract segments of these axons eliminated (Stanfield and O'Leary, 1985; O'Leary and Stanfield, 1986). This, of course, is quite similar to the present results. However, an important difference is that after the occipital pyramidal tract axons are eliminated, the pathway along which they developed, the medullary pyramid, remains and carries the definitive corticospinal axons arising from other cortical regions, while apparently no remnant of the postmamillary component of the fornix is retained.

While the postmamillary component of the fornix is not maintained in adult rats (Swanson and Cowan, 1977; Torigoe et al., 1986a; and this study), such a projection apparently is present in mature animals in other species. This was first described in experimental material by Edinger and Wallenberg (1902) using the Marchi method following hippocampal lesions in adult rabbits. Interestingly, in one group of rabbits (gewöhnlicken Hauskaninchen) and in white mice, they were unable to find any evidence for a postmamillary component; in another strain of rabbits (Riesen-Lapins), though, this component was well developed-in fact, only a small contingent of fibers was seen entering into the mamillary bodies. The distribution of the postmamillary fibers we see in the neonatal rats is quite similar to what Edinger and Wallenberg (1902) described in this latter strain of rabbits (compare their Fig. 10 with our Fig. 2). Some years later, Gerebtzoff (1941), using the Marchi method, as well as Sprague and Meyer (1950), using the Glees technique, confirmed the existence of a postmamillary component to the fornix in the rabbit, although the descriptions of the distribution of these fibers differ in these studies. Nauta (1958), using the Nauta-Gygax technique in cats, described the postmamillary component of the fornix extending into the rostral region of the midbrain central gray as being "quite massive." Yet according to a recent study, the postmamillary component of the fornix seems to be of relatively minor importance in the squirrel monkey (Poletti and Creswell, 1977).

Marked variability is also found in the descriptions of the magnitude, or even the presence, of the postmamillary component of the fornix among various species in studies utilizing normal fiber strains (von Gudden, 1881; Ganser, 1882; Vogt, 1898: Tello, 1936). An extreme situation has been described in the brain of the African elephant, in which a well-developed fornix passes the mamillary bodies and breaks into fascicles that continue caudally with only a very small number of tibers entering the mamillary bodies themselves (Diepen et al., 1956). Of course, it is not possible in normal material to determine what, if any, portion of the fiber tracts that are followed caudal to the mamillary complex actually arises in the hippocampal region.
That this projection which we find transiently present in developing rats is maintained and elaborated in some species suggests to us an explanation for the occurrence of this form of regressive phenomena. It may well be that whatever cues the fibers of the fornix follow as they pass the mamillary bodies cues which may constitute what has been termed a "substrate pathway" (Katz and Lasek, 1979)-are present in the brains of all developing mammals and in all, the fibers of the fornix initially respond to these cues similarly and follow this pathway. In some species this projection is subsequently elaborated and maintained, while in others it is eliminated. Thus, it is neither the "substrate pathway" (which may be laid down rather early, both in ontogeny and in phylogeny) nor the initial response of the growing axons to it which varies among species, but, rather, what differs exerts its effect later in development and has more to do with the maintenance of projections than with their initiation. We should expect that such a phenomenon would not be unique to the development of the fornix and that there will be other instances of differences among the adults of various species in the distribution of what are clearly homologous pathways that will be found to be the result of the elimination in some species and maintenance in others of a projection that is present during the development of all.

An obvious issue raised by our findings is the nature of the cues responsible for the trajectory followed by the axons of the postmamillary component of the fornix. While a definitive statement about this cannot yet be made, it seems likely that the fibers of the fornix grow past the mamillary bodies upon some previously extended axonal bundles. Of course it is well known that axons tend to fasciculate, and thus late-arriving axons tend to grow along previously extended fiber bundles. This is important in the present context since it seems that many of the fiber bundles within the region of the mamillary bodies are already established well before the arrival of the fibers of the fornix. There is virtually no experimental evidence outside of that presented here to establish this point, but the observations of numerous early workers on embryonic series from a variety of mammallian species are fairly consistent with regard to the relative timing of the development of the major fiber tracts in this region: (1) The fasciculus retroflexus and the mamillotegmental tract are among the first formed bundles in this region, and of these, the fasciculus retroflexus is often seen as arising earlier; (2) the mamillothalamic tract emerges from the principal mamillary tract at a somewhat later stage; and (3) at about this same stage, if not later, the fornix arrives within the region of the mamillary bodies (His, 1904; Droogleever-Fortuyn, 1912; van Valkenburg, 1912; Shaner, 1932; Tello, 1934, 1936).

A similar, but more recent, study (and the only comparable work utilizing albino rats) is that of Coggeshall (1964). He confirms in this species that all of the major fiber bundles just mentioned are present in the region of the mamillary bodies well before the arrival of the fornix on E21. ${ }^{3}$ Of course, as we have shown, although sharing a similar distribution with the efferent bundles of the mamillary nuclei (Cruce, 1977; Shen, 1983), the postmamillary component of the fornix does not follow upon these fiber tracts. Nor do these fibers follow any of the other major fiber tracts in this region. Still, the point to be made is that the fibers of the fornix arrive late with respect

\footnotetext{
${ }^{3}$ According to Coggeshall (1964), the fornix is first seen at the level of the Inamillary bodies on E22. Since he scored the sperm-positive day as E1, we have changed his E22 to E21 to be consistent with our own terminology.
} 
to other related pathways in the region and thus they may continue past the mamillary bodies upon one or more, yet to be identified, earlier formed projections. It would be of interest in this regard to investigate the development of the midbrain projections of the septal complex and of the hypothalamus, not only because these seem to be systems related to the fornix, but also since these projections are distributed, at least in part, similarly to the fibers of the postmamillary fornix (Nauta, 1956, 1958; Guillery, 1957; Valenstein and Nauta, 1959; Saper et al., 1976, 1979; Swanson and Cowan, 1979).

Finally, there is the issue of what factors may be involved in the initiation of the removal of the postmamillary fornix in the rat and/or its maintenance in other species. At this point we would only say that this at least seems amenable to experimental study. It would be premature, however, to speculate on the possibly related question of what the functional consequences of the resultant connectional differences may be, considering the state of our knowledge of the function of the neural systems involved.

\section{APPENDIX: Abbreviations used in figures}

\begin{tabular}{|c|c|}
\hline$A$, & Aqueduct of Sylvius \\
\hline$A D$ & Area dentata \\
\hline$A T N$ & Anterior thalamic nuclei \\
\hline CeM, & Centromedian thalamic nucleus \\
\hline$D k$ & Nucleus of Darkschewitsch \\
\hline$D L G$ & Dorsal lateral geniculate nucleus \\
\hline$D R$ & Dorsal raphe nucleus \\
\hline$D T$ & Dorsal tegmental nucleus \\
\hline$H$, & Habenula \\
\hline$I P$ & Interpenduncular nucleus \\
\hline$I P F$, & Interpenducular fossa \\
\hline$L C$ & Locus coeruleus \\
\hline$L V$ & Lateral ventricle \\
\hline$M B$ & Mamillary body \\
\hline$M D$ & Mediodorsal thalamic nucleus \\
\hline $\mathrm{MeV}$ & Mesencephalic nucleus \\
\hline$M R$ & Medial raphe nucleus \\
\hline$M S O$ & Medial superior olive \\
\hline$M i Z$ & Medial nucleus of the trapezoid body \\
\hline$M V$ & Motor nucleus of $\mathrm{V}$ \\
\hline$P C$ & Paracentral thalamic nucleus \\
\hline$P F$ & Parafascicular thalamic nucleus \\
\hline PONS, & Deep pontine nuclei \\
\hline$P T$ & Paratenial thalamic nucleus \\
\hline$R$ & Red nucleus \\
\hline$R S$, & Regio superior of Ammon's horn \\
\hline$R T$ & Reticular tegmental pontine nucleus \\
\hline$S C$, & Superior colliculus \\
\hline$S N$ & Substantia nigra \\
\hline$S T$ & Striatum \\
\hline SuM, & Supramamillary nucleus \\
\hline$T R$ & Thalamic reticular nucleus \\
\hline$V M$ & Ventral medial thalamic nucleus \\
\hline$V M b$ & Basal ventral medial thalamic nucleus \\
\hline$V T$ & Ventral tegmental nucleus \\
\hline$Z I$ & Zona incerta \\
\hline $3 V$ & Third ventricle \\
\hline $4 V$ & Fourth ventricle \\
\hline III , & Oculomotor nucleus \\
\hline$I V$ & Troclear nucleus \\
\hline
\end{tabular}

$\begin{array}{ll}a c, & \text { Anterior commissure } \\ d l f, & \text { Dorsal longitudinal fasciculus } \\ f, & \text { Fornix } \\ f,, & \text { Fimbria } \\ f r, & \text { Fasciculus retroflexus } \\ i c, & \text { Internal capsule } \\ m l, & \text { Medial lemniscus } \\ m l f, & \text { Medial longitudinal fasciculus } \\ m t, & \text { Mamillothalamic tract } \\ p m t, & \text { Principal mamillary tract } \\ p t, & \text { Pyramidal tract } \\ s m, & \text { Stria medullaris } \\ s t, & \text { Stria terminalis }\end{array}$

\section{References}

Azmitia, E. C., and M. Segal (1978) An autoradiographic analysis of the differential ascending projections of the dorsal and median raphe nuclei in the rat. J. Comp. Neurol. 179: 641-668.

Coggeshall, R. E. (1964) A study of diencephalic development in the albino rat. J. Comp. Neurol. 122: 241-269.

Cowan, W. M., D. I. Gottlieb, A. E. Hendrickson, J. L. Price, and T. A. Woolsey (1972) The autoradiographic demonstration of axonal connections in the central nervous system. Brain Res. 37: 21-51.

Cruce, J. A. F. (1977) An autoradiographic study of the descending connections of the mammillary nuclei of the rat. J. Comp. Neurol. 176: 631-644.

Diepen, R., P. Janssen, Fr. Engelhardt, and H. Spatz (1956) Recherches sur le cerveau de l'elephant d'Afrique (Loxodonta africana Blum). II. Donnees sur l'hypothalamus. Acta Neurol. Belg. 11: 759-788.

Donovan, M. K., and J. M. Wyss (1983) Evidence for some collateralization between cortical and diencephalic efferent axons of the rat subicular cortex. Brain Res. 259: 181-192.

Droogleever-Fortuyn, Ae. B. (1912) Die Ontogenie der Kerne des Zwischenhirns beim Kaninchen. Arch. Anat. Phys. Anat. Abtlg. (Leipzig) 303-352.

Edinger, L., and A. Wallenberg (1902) Untersuchungen uber den Fornix und das Corpus mamillare. Arch. Psychiatr. Nervenkr. 35: 1-21.

Ganser, S. (1882) Vergleichend-anatomische Studien uber das Gehims des Maulwulfs. Morphol. Jahrb. 7: 591-725.

Gerebtzoff, M. A. (1941) Note anatomo-experimentale sur le fornix, la corne d'Ammon et leurs relations avec diverses structures encephaliques, notamment l'epiphyse. J. Belg. Neurol. Psychiatr. 41: 199 206.

Guillery, R. W. (1957) Degeneration in the hypothalamic connexions of the albino rat. J. Anat. 91: 91-115.

His, W. (1904) Die Entwicklung des Menschlichen Gehirns Wahrend der Ersten Monate, Hirzel, Leipzig.

Irle, E., M. Sarter, W. O. Guldin, and H. J. Markowitsch (1984) Afferents to the ventral tegmental nucleus of Gudden in the mouse, rat, and cat. J. Comp. Neurol. 228: 509-541.

Ivy, G. O., and H. P. Killackey (1982) Ontogenetic changes in the projections of neocortical neurons. J. Neurosci. 2: 735-743.

Katz, M., and R. J. Lasek (1979) Substrate pathways which guide growing axons in Xenopus embryos. J. Comp. Neurol. 183: 817-832.

Killackey, H. P., and G. R. Belford (1979) The formation of afferent patterns in the somatosensory cortex of the neonatal rat. J. Comp. Neurol. 183: 285-304.

Künzle, H. (1977) Evidence for selective axon-terminal uptake and retrograde transport of label in cortico- and rubrospinal systems after injections of ${ }^{3} \mathrm{H}$-proline. Exp. Brain Res. 28: 125-132.

LeVay, S., and H. Sherk (1983) Retrograde transport of $\left[{ }^{3} \mathrm{H}\right]$ proline: A widespread phenomenon in the central nervous system. Brain Res. 271: 131-134.

Lund, R. D., and M. J. Mustari (1977) Development of the geniculocortical pathway in rats. J. Comp. Neurol. 173: 289-306.

Meibach, R. L., and A. Siegel (1975) The origin of fornix fibers which project to the mammillary bodies in the rat: A horseradish peroxidase study. Brain Res. 88: 508-512.

Mesulam, M.-M. (1978) Tetramethyl benzidine for horseradish peroxidase neurohistochemistry: A non-carcinogenic blue reaction-prod- 
uct with superior sensitivity for visualizing neural afferents and efferents. J. Histochem. Cytochem. 26: 106-117.

Nauta, W. J. H. (1956) An experimental study of the fornix system in the rat. J. Comp. Neurol. 104: 247-271.

Nauta, W. J. H. (1958) Hippocampal projections and related neural pathways to the midbrain in the cat. Brain $81: 319-340$.

O'Leary, D. D. M., and B. B. Stanfield (1985) Occipital cortical neurons with transient pyramidal tract axons extend and maintain collaterals to subcortical but not intracortical targets. Brain Res. 336: 326-333.

O'Leary, D. D. M., and B. B. Stanfield (1986) A transient pyramidal tract projection from the visual cortex in the hamster and its removal by selective collateral elimination. Dev. Brain Res. 27: 87-99.

Poletti, C. E., and G. Creswell (1977) Fornix system efferent projections in the squirrel monkey: An experimental degeneration study. J. Comp. Neurol. 175: 101-128.

Rakic, P. (1977) Prenatal development of the visual system in rhesus monkey. Phil. Trans. R. Soc. London [Biol.] 278: 245-260.

Reh, T., and K. Kalil (1981) Development of the pyramidal tract in the hamster. I. A light microscopic study. J. Comp. Neurol. 200: 7788.

Richardson, K. D., L. Jarrett, and E. H. Finke (1960) Embedding in epoxy resins for ultrathin sectioning in electron microscopy. Stain Technol. 35: 313-323.

Saper, C. B., L. W. Swanson, and W. M. Cowan (1976) The efferent connections of the ventromedial nucleus of the hypothalamus of the rat. J. Comp. Neurol. 169: 409-442.

Saper, C. B., L. W. Swanson, and W. M. Cowan (1979) An autoradiographic study of the efferent connections of the lateral hypothalamic area in the rat. J. Comp. Neurol. 183: 689-706.

Schreyer, D. J., and E. G. Jones (1982) Growth and target finding by axons of the corticospinal tract in prenatal and postnatal rats. Neuroscience 7 : 1837-1853.

Shaner, R. F. (1932) The development of the nuclei and tracts of the midbrain. J. Comp. Neurol. 55: 493-511.

Shatz, C. J., and M. B. Luskin (1986) The relationship between the geniculocortical afferents and their cortical target cells during development of the cat's primary visual cortex. J. Neurosci. 6: 3655-3668.

Shen, C. L. (1983) Efferent projections from the mammillary complex of the guinea pig: An autoradiographic study. Brain Res. Bull. 11: $43-59$.

Sprague, J. M., and M. Meyer (1950) An experimental study of the fornix in the rabbit. J. Anat. 84: 354-368.

Stanfield, B. B., and D. D. M. O'Leary (1985) The transient corticospinal projection from the occipital cortex during the postnatal development of the rat. J. Comp. Neurol. 238: 236-248.
Swanson, L. W., and W. M. Cowan (1975) Hippocampo-hypothalamic connections: Origin in subicular cortex, not Ammon's horn. Science 189: 303-304.

Swanson, L. W., and W. M. Cowan (1977) An autoradiographic study of the organization of the efferent connections of the hippocampal formation in the rat. J. Comp. Neurol. 172: 49-84.

Swanson, L. W., and W. M. Cowan (1979) The connections of the septal region in the rat. J. Comp. Neurol. 186: 621-656.

Tello, J. F. (1934) Beitrag zur Kenntnis der Entwicklung des Corpus mamillare bei der Maus. Z. Anat. Forsch. 36: 622-630.

Tello, J. F. (1936) Evolution, structure et connexions du corps mamillaire chez d'autres mammiferes. Trab. Lab. Invest. Biol. Madrid 31 : $77-142$.

Torigoe, Y., R. H. I. Blanks, and W. Precht (1986a) Anatomical studies on the nucleus reticularis tegmenti pontis in the pigmented rat. I. Cytoarchitecture, topography, and cerebral cortical afferents. J. Comp. Neurol. 243: 71-87.

Torigoe, Y., R. H. I. Blanks, and W. Precht (1986b) Anatomical studies on the nucleus reticularis tegmenti pontis in the pigmented rat. II. Subcortical afferents demonstrated by the retrograde transport of horseradish peroxidase. J. Comp. Neurol. 243: 88-105.

Valenstein, E. S., and W. J. H. Nauta (1959) A comparison of the distribution of the fornix system in the rat, guinea pig, cat, and monkey. J. Comp. Neurol. 113: 337-363

van der Kooy, D., H. G. J. M. Kuypers, and C. E. Catsman-Berrevoets (1978) Single mammillary body cells with divergent axon collaterals. Demonstration by a simple, fluorescent retrograde double labeling technique in the rat. Brain Res. 158: 189-196.

van Valkenburg, C. T. (1912) Caudal connections of the corpus mammillare. Proc. R. Acad. Amst. 14: 1118-1121.

Vogt, O. (1898) Sur le pilier anterieur du trigone. C. R. Soc. Biol. 50: 207-208.

von Gudden, B. (1881) Beitrage zur Kenntniss des Corpus mammillare und der sogenannten Schenkel des Fornix. Arch. Psychiatr. Nervenkr. 11: 428-452.

Wise, S. P., and E. G. Jones (1978) Developmental studies of thalamocortical and commissural connections in the rat somatic sensory cortex. J. Comp. Neurol. 175: 187-208.

Wise, S. P., S. H. C. Hendry, and E. G. Jones (1977) Prenatal development of sensorimotor cortical projections in cats. Brain Res. 138: 538-544.

Wyss, J. M., and K. Sripanidkulchai (1984) The topography of the mesencephalic and pontine projections from the cingulate cortex of the rat. Brain Res. 293: 1-15. 